\title{
A large-scale implementation of predictive learning analytics in higher education: the teachers' role and perspective
}

\author{
Christothea Herodotou $^{1}$ (iD) $\cdot$ Bart Rienties $^{1} \cdot$ Avinash Boroowa $^{1} \cdot$ Zdenek Zdrahal $^{2}$. \\ Martin Hlosta ${ }^{2}$
}

Published online: 2 July 2019

(C) The Author(s) 2019

\begin{abstract}
By collecting longitudinal learner and learning data from a range of resources, predictive learning analytics (PLA) are used to identify learners who may not complete a course, typically described as being at risk. Mixed effects are observed as to how teachers perceive, use, and interpret PLA data, necessitating further research in this direction. The aim of this study is to evaluate whether providing teachers in a distance learning higher education institution with PLA data predicts students' performance and empowers teachers to identify and assist students at risk. Using principles of Technology Acceptance and Academic Resistance models, a university-wide, multi-methods study with 59 teachers, nine courses, and 1325 students revealed that teachers can positively affect students' performance when engaged with PLA. Follow-up semi-structured interviews illuminated teachers' actual uses of the predictive data and revealed its impact on teaching practices and intervention strategies to support students at risk.
\end{abstract}

Keywords Predictive learning analytics $\cdot$ Teachers $\cdot$ Student performance $\cdot$ Retention · Higher education

\section{Introduction}

With the increased availability of large datasets, powerful analytics engines (Joksimović et al. 2015; Macfadyen and Dawson 2010; Romero et al. 2013), and skilfully designed visualisations of analytics (Ali et al. 2012; Dyckhoff et al. 2012; González-Torres et al. 2013), institutions and teachers may be able to use the experience of the past to create supportive, insightful models of primary (and perhaps real-time) learning processes (Ferguson and Buckingham Shum 2012; Mor et al. 2015; Papamitsiou and Economides 2014). In recent years, several institutions have started to adopt predictive learning analytics (PLA) using a range of advanced computational techniques (e.g., Bayesian modelling, cluster analysis,

Christothea Herodotou

christothea.herodotou@open.ac.uk

1 Institute of Educational Technology, The Open University, Walton Hall, Milton Keynes MK7 6AA, UK

2 Knowledge Media Institute, The Open University, Walton Hall, Milton Keynes MK7 6AA, UK 
predictive modelling) to identify which students are going to pass a course, and which of them are at-risk (Calvert 2014; Gasevic et al. 2016; Joksimović et al. 2015; Tempelaar et al. 2015; Wolff et al. 2014), yet little evidence exist about their wide adoption in higher education (Viberg et al. 2018). PLA data may provide useful, complementary information to teachers to help them identify students at-risk while also allowing them to support other groups of students and maximise their potential.

As recognised by recent learning analytics research (Dyckhoff et al. 2012; Rienties et al. 2016; van Leeuwen et al. 2014; Verbert et al. 2013) and wider literature on the role of teachers in blended learning settings (e.g., Mazzolini and Maddison 2003; Norton et al. 2005; Rienties et al. 2013), teachers have an essential role to play in transforming insights gathered from PLA into actionable support and interventions that help students. Yet, for many teachers, it is a challenge to be able to filter relevant information from the virtual learning environment (VLE) in PLA tools, and access predictive data about each of their students. In particular, a lack of competence has been observed in extracting relevant information from learning analytics visualisations as well as taking corresponding pedagogical actions (van Leeuwen 2018). While we recognise that VLE and PLA tools provide rich and detailed information about student progression, they may also lead to information overload which may restrict teachers' abilities to provide effective support to learners (van Leeuwen et al. 2014). Also, PLA data can negatively impact learning if their applications are not well-routed into existing educational theory (Gasevic et al. 2015). A well-known application of PLA in education, Course Signals (Tanes et al. 2011), identified students 'at-risk' and provided warning signals to teachers and students. The authors analysed the content of feedback messages sent to students as a response to the signals received by the system. The type of feedback most often given to students was summative whereas instructive or process feedback on how to overcome difficulties was almost absent. Aligning with existing research, summative feedback had no effect on students' learning.

Although PLA might provide teachers with some powerful tools, several researchers (Gasevic et al. 2016; Greller and Drachsler 2012; Tempelaar et al. 2015) indicate that most institutions and teachers in particular may not be ready for PLA results. Indeed, recently several researchers reported mixed effects about providing PLA data and visualisations to teachers (Rienties et al. 2016; van Leeuwen et al. 2014, 2015). While these studies provide important insights about how teachers in relatively small-scale settings used simple learning analytics visualisations to identify groups of learners that were less active, to the best of our knowledge, no study has yet unpacked how teachers are using actual PLA data across large distance learning courses as well as the impact this activity may have on student learning outcomes.

This study reports on a university-wide implementation of PLA consisting of 59 teachers facilitating nine courses $(N=9)$ in a distance learning higher education institution. A multi-methods research was conducted to first, measure the impact of teachers' use of PLA on students' performance. Such understanding is essential as it can provide insights about whether any reported usage of PLA by teachers has an impact or not on students' performance, thus concluding on whether PLA tools, when used by teachers, are successful or not in terms of benefiting students and their learning. Also, it can inform our understanding and interpretation of qualitative data collected from interviews with teachers about PLA perceptions and usage patterns. For instance, if PLA usage is found to improve learning, understanding how teachers make use of it could provide evidence of best practice as to how PLA tools could be used to support learning. Alternatively, if PLA usage is found not to improve learning, we could seek to understand whether actual uses (e.g., approaches and frequency of contacting students at risk) may explain the lack of any learning improvement 
thus informing future evaluations of PLA. Second, using semi-structured interviews, we aimed to unpack whether and how participating teachers made use of PLA data to support students and identify the underlying reasons explaining teaching practices. We made use of two theoretical lenses, the Technology Acceptance (Davis 1989; Šumak et al. 2011) and Academic Resistance Models (Piderit 2000; Rienties 2014), that may explain why some teachers pro-actively engaged with PLA while others chose not to do so. The Technology Acceptance model (TAM) explains users' intention to use a technology by the extent to which the user believes that the technology is beneficial (perceived usefulness) and whether the technology is easy to use (perceived easy-of-use). Previous research has consistently found that one common factor as to why teachers start and continue to use technology in their practice is their acceptance of technology (Rienties et al. 2016; Sumak et al. 2011; Teo 2010; Teo and Zhou 2016), in particular technology's perceived ease of use and perceived usefulness.

The academic resistance model (ARM) explains organisational adaptation or resistance in terms of employees' attitudes. Attitudes are perceived as a multidimensional concept comprised of: (a) cognitive attitudes referring to whether a technology is positively, negatively or neutrally evaluated by users, (b) emotional attitudes referring to feelings and emotions experienced when using the technology, and (c) intentional attitudes referring to intention to resist or plan to use the technology in the future. Different reactions may characterise each dimension, for example, a strongly positive cognitive attitude maybe accompanied by a strongly negative emotional response. Tensions between cognitive and emotional attitudes may inhibit adoption of online interventions by teachers and lead to AR (Rienties 2014). Resistance was originally suggested as influencing change in organisational structures. According to Piderit (2000, p. 783), "[s]uccessful organisational adaptation is increasingly reliant on generating employee support and enthusiasm for proposed changes, rather than merely overcoming resistance.(p. 783)" Some teachers may embrace new technologies and PLA approaches in particular while others may be more reticent, which may be explained by the above models.

In order to address our overall research aim of unpacking how the engagement of teachers with PLA might positively or negatively support students' performance, we will first provide a review of literature on PLA, TAM, and AR. Second, we will explain the OU Analyse system, which is the in-house built PLA system by the Open University UK.

\section{Providing predictive learning analytics (PLA) to teachers in online learning settings}

An often cited model of visualisation of learning analytics tools (Dyckhoff et al. (2012) distinguishes four different stages of use: (a) data-gathering of students' activities in VLE, (b) data collection and data mining using learning analytics techniques, (c) visualisation of student activities in a widget, application, or VLE, and (d) reflection by the teacher. Teachers are expected to quickly interpret visualisations, understand their impact on teaching and learning, and judge their effectiveness (Dyckhoff et al. (2012, p. 60). Ideally, PLA visualisation should lead teachers to action in terms of teaching interventions, yet there is no guarantee that teachers will be able to make informed teaching interventions and act accordingly (Rienties et al. 2016).

There is a limited understanding as to how teachers make use of learning analytics visualisation (van Leeuwen et al. (2015, p. 28). In a small experimental study of 28 high 
school and student teachers, van Leeuwen et al. (2014) found that teachers who received learning analytics visualisations of collaboration activities (i.e., authentic student data were converted into simulation vignettes of students who had participation or discussion problems) were better able to identify participation problems. Furthermore, these teachers intervened more often with "problematic" groups as opposed to a control group of teachers who did not receive learning analytics visualisations. Yet, a follow-up study with 40 teachers visualisation (van Leeuwen et al. (2015, p. 28) showed that teachers with access to learning analytics data were not better at detecting problematic groups but they could provide more support to students experiencing problems. In a qualitative study, van Leeuwen (2018) examined the perceptions of seven teachers when weekly learning analytics reports were made available to them. Learning analytics insights were found to influence teachers' behaviour, by opening up interaction and communication between the teachers and students, leading to pedagogical interventions. In a four-year study of fine-grained data collection amongst 34 teachers, McKenney and Mor (2015) indicated that the teachers' professional development was enhanced (i.e., they learn from the process) by engaging with learning analytics software and that teachers were able to develop better curriculum materials.

In distance learning settings, the role of teachers in providing support through PLA data is crucial. The teachers' guidance and assistance are found to significantly impact learning outcomes in particular, completion of students' learning activities (Ma et al. 2015). While distance learning teachers may have access to a lot of fine-grained clicking data to support them in comparison to teachers in face-to-face or blended settings (Richardson 2013; Wolff et al. 2013), they will often not receive visual and oral clues about their students as teachers in face-to-face or blended settings (Simpson 2013). Research indicated that VLE engagement, in particular engagement with assessment activities, was positively predicting performance (Calvert 2014), while Bayesian modelling indicated that the learning paths of successful students were significantly different from those of "failing" students (Kuzilek et al. 2015; Wolff et al. 2014). At the same time, in many distance learning settings most teachers are recruited externally given the sheer scale of operations (contract-based). These conditions may place obstacles to teachers and their continuous monitoring of PLA data.

\section{Technology acceptance}

A range of studies have found that users' technology-acceptance, as conceptualised in the technology acceptance model (TAM) by Davis et al. (1989), can have a substantial impact on the adoption of information systems. TAM is a widely used model and has proved to be highly informative in explaining teachers' uptake of educational technology (Šumak et al. 2011; Teo and Zhou 2016). Developed models have successfully been applied to educational settings (Pynoo et al. 2011; Sanchez-Franco 2010; Šumak et al. 2011). The TAM model is founded on the well-established theory of Planned Behaviour (Ajzen 1991), which states that human behaviour is directly preceded by the intention to perform this behaviour. In turn, three factors are found to influence intentions: personal beliefs about one's own behaviour, one's norms, and the (perceived) amount of behavioural control an individual has.

Building on this theory, TAM states that a user's intention to use technology is influenced by two main factors: perceived usefulness (PU: e.g., the extent to which a teacher believes the use of PLA dashboards will, for example, enhance the quality of their teaching or increase academic retention) and perceived ease of use (PEU: e.g., the perceived effort 
needed to use PLA). The influence of PU and PEU has consistently been shown in educational research (Pynoo et al. 2011; Teo 2010; Teo and Zhou 2016; Ali et al. 2013; Pituch and Lee 2006; Sanchez-Franco 2010). For example, Teo (2010) found that PU and PEU were key determinants of the attitudes towards computer use of 239 pre-service teachers. Also, Rienties et al. (2018) identified that, out of 95 teaching staff, the great majority (68\%) perceived learning analytics visualisations as being useful (PU), yet only $34 \%$ as easy to use (PEU) and this is more likely due to the number of tools examined concurrently and their early level of development. These insights indicate the teachers' recognition of the significance of using analytics to support students yet they also raised the need for additional support and teacher training that can facilitate usage.

\section{Academic resistance model}

A second main reason why some teachers might be more willing to adopt PLA may be a resistance or ambivalence towards change. According to Piderit (2000, p. 783), "[s]uccessful organisational adaptation is increasingly reliant on generating employee support and enthusiasm for proposed changes, rather than merely overcoming resistance." As argued by Hanson (2009, p. 557), many studies tend "to blame the individual academic and attribute delays or failure in implementation to an oversimplification of negative attributes, ill-will, indolence, ineptitude or indiscipline on the part of those at whom the change is aimed ... or to portray resistance to change as irrational."

In her review of "resistance" literature, Piderit (2000) argued that the ambivalence of academics, in particular towards change, needs to be understood against three dimensions of attitudes: cognitive, emotional, and intentional. Academic resistance models (ARM) explain resistance (or having mixed feelings) about PLA in terms of cognitive (e.g., beliefs about PLA that may help to accurately identify students at risk), emotional (e.g., feelings about being followed by PLA systems; being assessed about how well a teacher provides support to students; anxiety towards a future where PLA could replace teachers) and intentional attitudes (i.e., teachers' plans to take an action). The ARM could help illuminate teachers' perceptions about the use of learning analytics and whether these relate to specific beliefs, feelings, or future plans. For example, in a large-scale organisational change implementation across 629 courses from paper to online student evaluation, Rienties (2014) found that the vast majority of academics were negative about this organisational change. This finding was rather surprising given that, from a cognitive perspective, participants recognised that student evaluations were provided faster, with comparable evaluation scores for teachers, yet with three times more qualitative feedback. Follow-up interviews revealed that academics were at the same time experiencing anxiety (i.e., emotional dimension) with the idea that senior management could more intensively monitor their behaviour and use this for promotion/demotion.

In this study, ARM and TAM are used in combination as they complement each other and can provide unique insights in relation to the reasons potentially explaining usage of PLA by teachers. In particular, TAM advocates that usage is explained by technology's easy-of-use and perceived usefulness whereas ARM explains usage in terms of cognitive, emotional and intentional resistance to change. TAM is more focused on the design and use of a technology whereas ARM on individuals' attitudes to change. One may argue that there is also a degree of overlap between the two models with, for example, perceived usefulness being an example of a cognitive attitude (ARM), and anxiety when using PLA due 
to complexity of visualisations explained by both TAM through "perceived easy-of-use" and ARM as an indication of emotional resistance.

\section{PLA at a distance learning institution: OU analyse}

Learning analytics dashboards have been discussed in the literature in relation to their potential benefits to providing feedback opportunities and supporting learning (Bodily and Verbert 2017). Yet, few studies have examined their actual impact on behaviour, achievement and skills (Bodily and Verbert 2017; Verbert et al. 2013). For example, Gutiérrez et al. (2018) generated evidence about the effectiveness of learning analytics dashboards for academic advising and support of decision-making processes. In particular, experts advisers were found to assess more and difficult cases of students who failed their courses while inexperienced advisers were shown to make informed decision in the same amount of time as experienced ones. Towards this direction, in this study we aim to generate evidence about the effectiveness of OU analyse (OUA).

OUA is a PLA system designed at the Open University UK, which uses a range of advanced statistical and machine learning approaches to predict students at-risk so that cost-effective interventions can be made. The primary objective of OUA is the early identification of students who may fail to submit their next teacher marked assessment (TMA). Four to six TMAs per course are typically requested from students. Combining predictions about whether a student will submit their next TMA, the system also provides information about whether students will complete a course. This is the 'overall' system prediction about a student's performance. OUA was designed as a tool that would inform teachers about their students' behaviour and motivate them towards taking an action when students are at-risk of not submitting their next assignment. The broader objective was to increase students' retention and completion of their studies.

Predictions of students at-risk of not submitting their next TMA are constructed by machine learning algorithms that make use of two types of data: (a) static data: demographics, such as age, gender, geographic region, previous education, and (b) behavioural data: students' interactions within the VLE hosting a course. These sources of data were shown to be significant indicators of predicting students' assignment submission (Kuzilek et al. 2015; Wolff et al. 2013, 2014). The resources a student may interact with have semantic labels called "activity types." Examples of activity types are: forum, content, resource, glossary, and wiki. All students' interactions with the VLE are recorded and saved in a database.

OUA employs three machine learning methods: (1) Naïve Bayes classifier (NB), (2) Classification and regression tree (CART), (3) k-Nearest Neighbours (k-NN). Those are used to develop four predictive models: (1) NB, (2) CART, (3) k-NN with demographic data, and (4) k-NN with VLE data. Combining results from these four models was shown to improve overall predictive performance. Two versions of k-NN was used due to the different nature of the values measured, i.e. numeric VLE data and categorical demographic data. These four models consider different properties of student data and complement each other. Each model classifies each student into classes: (a) will/will-not submit next assessment and (b) will fail/pass the course. The final verdict of the prediction is done by combining the outcomes and using voting techniques from all four models (Kuzilek et al. 2015; Wolff et al. 2013, 2014). In brief, the result of the prediction is 'will-not submit next assignment' if three or all four models give a prediction of 'will-not submit'. The result of the prediction is 'will submit' if zero, one, or two models only vote 'will-not submit'. 


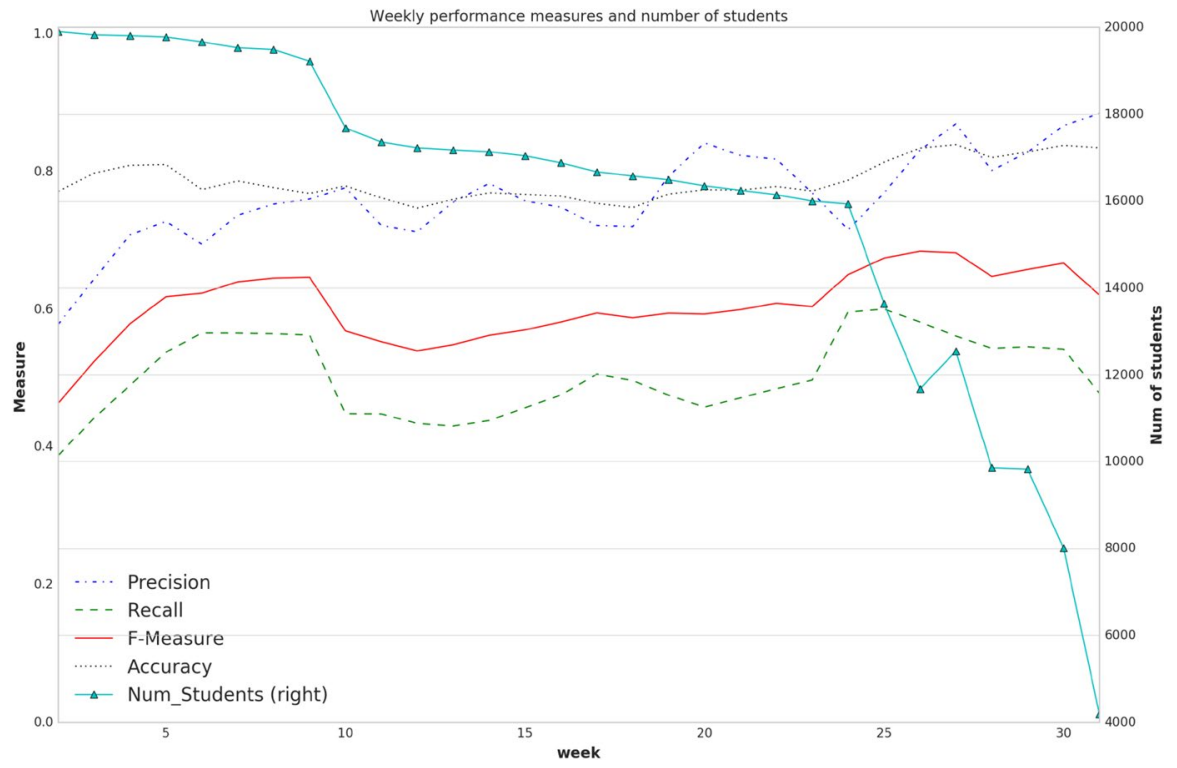

Fig. 1 Precision, recall, F-measure and accuracy of OUA

Predictions are calculated in two steps. First, predictive models are constructed by machine learning methods from legacy data recorded in the previous presentation of the same course. Second, student performance is predicted by the predictive models and the student data of the current presentation. Machine learning methods aim at constructing predictive models that capture data patterns for e.g., succeeding, failing or withdrawing in formative/summative assessments and the course. OUA algorithms make use of weekly aggregates. The system applies weekly information theoretic criteria to select 4-6 activity types with the minimum redundancy and maximum information content and most informative about the outcome of the next assessments. These activity types are used to build predictive models. Moreover, the frequency of learners' use of activities with selected activity types indicates which study material learners visited and how many times. Activity types that are not used point to a potential gap in knowledge and are used by the system as an input for individualised study recommender.

To assess the quality of predictions by OUA, in each week confusion matrix values (True Positive, True Negative, False Positive, False Negative) for all the courses are summed up, creating one confusion matrix per week. From this matrix, the performance metrics, such as accuracy, are computed. By doing this, the courses with larger number of students have higher impact on the performance metrics. Precision, Recall, F-measure, and Accuracy for the courses under study are then constructed (see Fig. 1). Precision denotes the proportion of students that OUA correctly identified as "not submit" out of all students identified as "not submit". Recall is the proportion of those students correctly identified as "not submit" of all students that have not submitted an assignment; F-Score is a harmonic mean of Precision and Recall, and Accuracy is the proportion of all correct predictions to the total number of students. The class under examination is students "at risk" ("willnot submit next assignment'); in each week, only students who do not submit their assignments are subject to predictions. Teachers can see all the students in the dashboard, yet 


\section{AAA 2015] - Week 16}

Time machine (choose week): 16

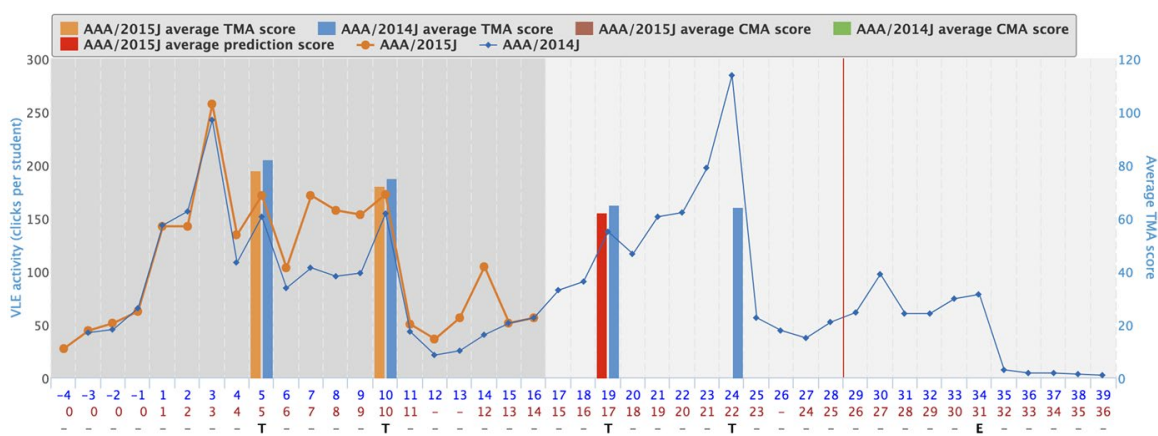

Fig. 2 A section of the OUA dashboard illustrating the average performance of the whole cohort of students in a respective course. The current course presentation (yellow) is compared to the previous one (dark blue). The bars show the average assignment scores, while the lines indicate the average number of clicks per student per week in VLE activities (Color figure online)

no predictions are produced for those who submit the coming teacher-mark assignment as the result of this submission is already known (i.e., they submitted). In Fig. 1, "number of students" refers to students who have not submitted their next assignment, that is the assignment that is currently being predicted. Precision increases the closer the assignment submission deadline is. Recall increases after the deadline as the model can identify more students due to their low activity. Accuracy is relatively the same across presentations and increases in the end of a course presentation, more likely due to the more information the system knows about students as well as the fact that more courses that are easier to predict remain in the analysis. F-measure, the harmonic mean of precision and recall, increases towards the middle and end of course presentations.

Teachers access OUA data through the OUA dashboard (Figs. 2, 3, 4). Accessing the dashboard is separate to accessing any other information about students that is hosted in the University's management system. The dashboard provides teachers with information about how their course compares to the previous year's presentation in terms of students' engagement with VLE. Also, by combing evidence from the VLE and demographics, it gives teachers access to predictions about whether their students would submit their next assignment. Contact with students takes place outside the OUA dashboard, either by emailing, texting, or phoning students. Information about the process of getting in touch and the responsiveness of students is recorded in the University's management system.

\section{Aim of this study}

While several researchers in the learning analytics field have indicated a need for professional development, training, and support for teachers to help them use the complex and 


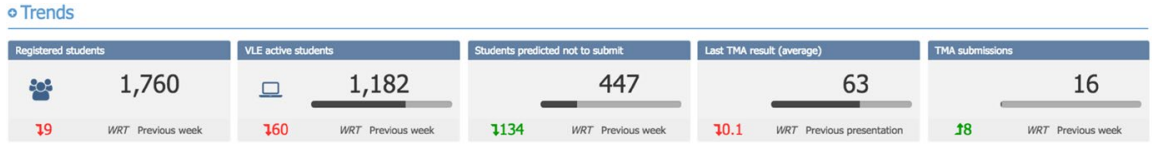

\section{- Predictions}

\begin{tabular}{|c|c|c|c|c|c|c|c|}
\hline $25 \div$ & & & & & & Export & Select columns - \\
\hline \multicolumn{5}{|c|}{ Student Information } & \multicolumn{3}{|c|}{ Next TMA predictions } \\
\hline Student PI & Name & $\hat{\imath}$ & TMA & a & Submission $\wedge$ & Risk of NS & Grade \\
\hline$A X X X X X X X X$ & Student1 & & & & Not Submit & U & Not Submit \\
\hline$A X X X X X X X X$ & Student2 & & & & Submit & 1 & Pass 3 \\
\hline$A X X X X X X X$ & Student3 & & & & Not Submit & & Not Submit \\
\hline$A X X X X X X X$ & Student4 & & & & Submit & 1 & Pass 2 \\
\hline$A X X X X X X X$ & Student5 & & & & Submit & I & Pass 3 \\
\hline$A \times C X X X O X X$ & Student6 & & & & Submit & 1 & Pass 3 \\
\hline$A X X X X X X X X$ & Student7 & & & & $\mathrm{N} / \mathrm{A}$ & N/A & N/A \\
\hline$A X X X X X X X X$ & Student8 & & & & Submit & & Pass 3 \\
\hline$A X X X X X X X$ & Student9 & & & & Submit & a & Pass 4 \\
\hline$A X X X X X X X$ & Student10 & & & & Not Submit & & Not Submit \\
\hline$A X X X X X X X X$ & Student11 & & & & Submit & 1 & Pass 2 \\
\hline$A X X X X X X X X$ & Student12 & & & & Submit & 1 & Pass 2 \\
\hline$A X X X X X X X X$ & Student13 & & & & Submit & 1 & Pass 4 \\
\hline$A X X X X X X X$ & Student14 & & & & Submit & I & Pass 3 \\
\hline$A X X X X X X X$ & Student15 & & & & Submit & & Pass 4 \\
\hline$A X X X X X X X X$ & Student16 & & & & Submit & $\square$ & Pass 3 \\
\hline
\end{tabular}

Fig. 3 A section of OUA Dashboard showing the overall statistics of the current course presentation (trends). At the bottom part, a list of all students with their TMA predictions in a given week is presented. Predictions are generated for all students who have not yet submitted their next TMA in the given week. Predictions are not generated the week a student submits their assignment. Such students (e.g., Student7) are flagged as $\mathrm{S}$ (submitted)

dynamic insights from learning analytics (Ali et al. 2012; McKenney and Mor 2015; Rienties and Toetenel 2016; van Leeuwen et al. 2014), few studies have unpacked how teachers perceive and use insights from predictive analytics in their daily practice as well as how teachers' PLA practices may relate to specific student outcomes (e.g., passing or failing a course). Such insight would be valuable as existing studies suggest that teaching practices can have a positive impact on student performance in online settings. For example, examining more than 500 students, Liu and Cavanaugh (2012) found a significant influence of teachers' comments and timely and constructive feedback on students' final scores in online algebra modules. In another study, Ma et al. (2015) analysed log data from 900 courses and found that the teachers' guidance has a significant effect on the completion of students' learning activities. In a recent systematic review, Viberg et al. (2018) noted improvements from using learning analytics in student learning outcomes and the teaching practice (support), yet these are very limited.

In this paper, we adopted a two-phase multi-methods methodology to understand how teachers used, interpreted and integrated OUA into their teaching practices. In Phase 1, 


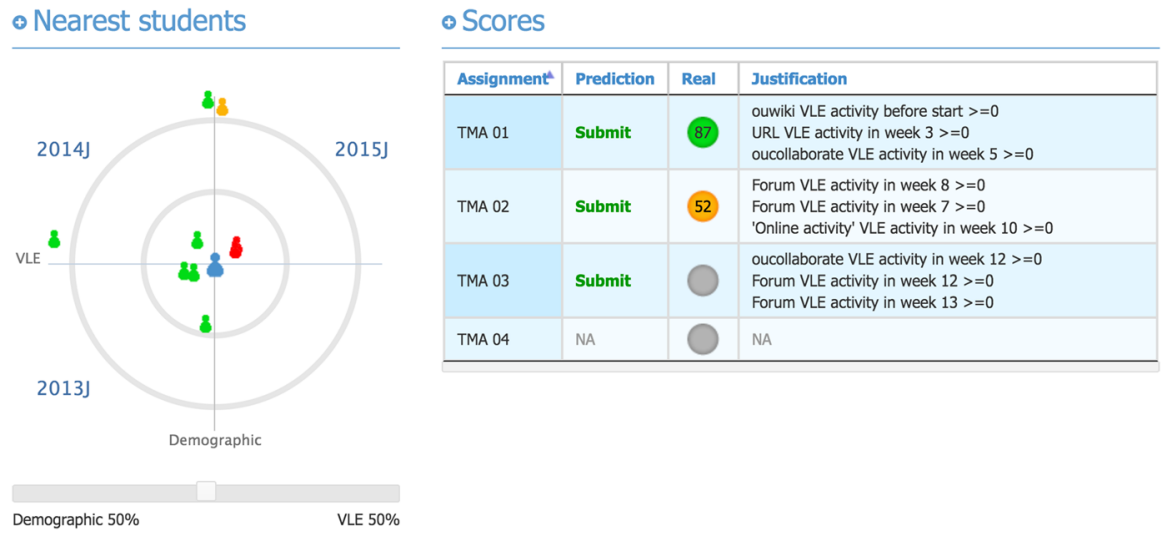

Fig. 4 The individual student view of OUA dashboard showing dynamic information about individual students. The target visualises similarity between the selected student and their nearest neighbours measured in terms of VLE activities (horizontal axes) and demographic parameters (vertical axes). In the table with scores, the previous predictions of the student in the current presentation are shown along with the actual score if their assignment has been marked

we explored from a quantitative perspective how the performance of 1325 students was influenced by the use of OUA by 59 teachers across nine online courses. Building on previous PLA research (e.g., Herodotou et al. 2017, 2019; Rienties et al. 2016), we specifically considered for learners' characteristics, such as age, gender, previous grades, ethnicity, successful completion of previous courses [e.g., (e.g., Hachey et al. 2014)], VLE design and course-specific characteristics (e.g., Gasevic et al. 2016; Rienties and Toetenel 2016), and the teacher's role and interaction with students (e.g., Arbaugh 2014).

In this study, we expected that the successful prediction of student performance could be achieved with:

(a) student demographic data: gender, age, disability, ethnicity, education level, Index of Multiple Deprivation (IMD band), ${ }^{1}$ students' previous experience of studying at a university (new versus continuous student), best previous course score achieved, and sum of previous credits achieved,

(b) design differences across participating courses, and

(c) teaching features, including number of course presentations each teacher completed, workload as measured by the number of students per course presentation assigned to each teacher, and the average weekly usage of OUA dashboard per teacher.

Therefore, our first Research Question (RQ1) explored the potential impact of teachers' usage of OUA on students' performance:

RQ1 To what extent does engagement of teachers with OUA predict students' performance (i.e., pass and completion rates) ${ }^{2}$

\footnotetext{
${ }^{1}$ IMD band is a UK measure of deprivation indicating deprived areas in English local councils.

2 Completion refers to submitting the final assignment of a course. Pass refers to passing the course that is achieving at least $40 \%$.
} 
In Phase 2, in line with (Boyatzis 1998; Herodotou et al. 2017), we took a fine-grained, qualitative perspective to better understand how teachers made sense of PLA in their daily practice. Using the two lenses of TAM and AR, we explored the experiences of six teachers who used OUA during those courses to unpack why some teachers actively used the system, while others might not have actively engaged with it. By triangulating the OUA experiences of those teachers with their actual OUA usage data, we explored the following two Research Questions:

RQ2 How do teachers make use of OUA data and visualisations to support teaching and learning?

RQ3 Using TAM and ARM as theoretical lenses, which factors might explain teachers' use of OUA?

\section{Methodology}

Nine distance learning, year 1 (Level 1) courses $(N=9)$ took part in this multi-methods study. Some of the courses have optional face-to-face elements, such as meetings between students and teachers to discuss course-related issues. A range of activities is featured in these courses including assimilative activities, finding and handling information, communication, productive, experiential, interactive activities, and assessment. Each course emphasises some or most of these activities. Assessment criteria vary between courses, and include formative and summative assignments and examinations (Nguyen et al. 2017). Participating courses were self-selected. Courses expressing interest in participating were included in this study.

Each course has a number of teachers, so-called Associate Lecturers (ALs), who support students at a distance. Each AL is responsible for a group of 15-20 students and their role is to provide support and guidance to students in their group when needed. ALs are required to know how to use information communication technology for teaching and supporting students, accessing information in relation to students, facilitating contact with academic units, and dealing with administrative responsibilities. Data were collected from the cohort of students registered at the nine courses under study in 2015-2016. Participating teachers were volunteers interested in joining the project. Oral consent by teachers was gained by accepting to join the project. In terms of students' consent, the OU Policy on Ethical use of Student Data for Learning Analytics (Open University UK 2014) informs students that their interactions are captured and may be used where there is likely to be an expected benefit to learning. Informed consent applies at the point of reservation or registration on to a course or qualification.

Participating teachers were offered the option of joining online briefing sessions about what predictive analytics are, what tools including OUA are available, and how they could be used to support the teaching practice. Yet, participation was very limited in the range of $5-6 \%$, despite scheduling the sessions well in advance.

\section{Sample}

Participating teachers (see Table 1) were self-selected with the obvious (self-selecting) biases (Rienties et al. 2016; Torgerson and Torgerson 2008). No financial incentives were offered to participating teachers. Logging in data from 59 teachers with access to 
Table 1 Number of courses, teachers, and students participating in the study

\begin{tabular}{llcc}
\hline No & Course/year & Teachers & Students \\
\hline 1 & Arts-2015 & 3 & 55 \\
2 & Social science-2015 & 3 & 69 \\
3 & Education-2015 & 11 & 262 \\
4 & Health care-2015 & 2 & 24 \\
5 & Maths-2015 & 8 & 186 \\
6 & Engineering-2015 & 6 & 152 \\
7 & Technology-2015 & 11 & 239 \\
8 & Technology-2016 & 6 & 92 \\
9 & Law-2015 & 9 & 246 \\
& Total & 59 & 1325 \\
\hline
\end{tabular}

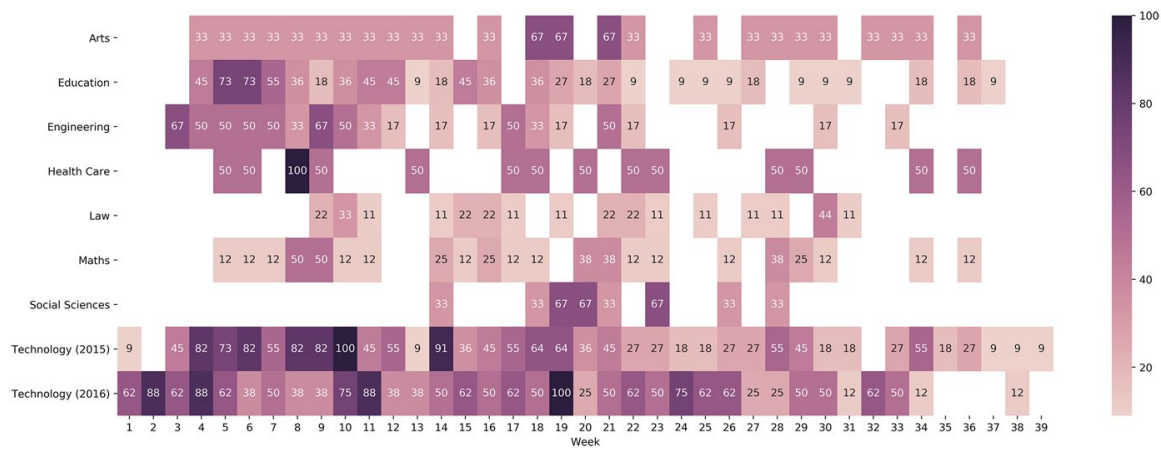

Fig. 5 Percentage of teachers accessing the OUA dashboard per week per course. $X$ axis indicates the respective week of the term for participating courses. $Y$ axis indicates the nine participating courses

OUA dashboard were collected. These data can provide us with insights about teachers' usage patterns and their relation (if any) to student performance.

\section{Methods of data collection and analysis}

\section{Phase 1: quantitative impact of OUA on students' performance}

In Phase 1, binary logistic regression analysis was performed to identify whether teachers' engagement with PLA through the OUA dashboard significantly predicts pass and completion rates (RQ1). Our unit of analysis were students $(N=1325)$. Course and teacher predictor indicators were group-level measures, created by combining data between the student and teacher/course levels. In particular, teacher-level data was constant within a group of students that was managed by a single teacher. Similarly, course-level data was constant within all students attending a single course. On the contrary, individual-level variables such as age and gender varied across all cases i.e., 1325 participating students. A binary logistic regression was used as dependent variables of completion (i.e., completed/not completed) and pass (i.e., passed/failed) rates were dichotomous (Gliner et al. 2011). 
The average weekly usage of OUA dashboard was captured by measuring the logging in activity of participating teachers (i.e., how often and when teachers accessed the system). Weekly usage statistics were gathered and aggregated on a course level to guarantee anonymity of respective teachers (see Fig. 5). Seven $(n=7)$ teachers did not access the dashboard at all. It is noted that this type of log file data entails certain limitations such as not informing about the OUA features teachers accessed and the amount of time they spend on the system; teachers may have identical numbers of OUA visits, yet differ in these other dimensions. Figure 5 shows the number of visits to the dashboard per week per course. The two courses with the highest frequency of access were Technology-2015 (i.e., course ran in year 2015) and Education. Substantially lower use was observed for Law, Maths, Social sciences, Technology-2016, Engineering (week 12 onwards), and Education (week 16 onwards). This trend indicates that, although teachers had access to OUA they did not access OUA predictions regularly.

Correlation analysis was performed before entering the variables into the regression to examine for multicollinearity. No variables were found to correlate highly or significantly.

\section{Phase 2: qualitative experiences of teachers using OUA}

In Phase 2, six individual semi-structured interviews with teachers who made use of OUA were conducted in order to explore RQ2 and RQ3. Emails were sent to all course chairs of the participating courses requesting for teachers-volunteers who could take part in the interviews. Teachers were invited to individual semi-structured interviews expected to last approximately $45 \mathrm{~min}$. Interview participants were self-selected.

Only six $(N=6)$ individuals from the engineering $(n=3)$, math $(n=2)$ and technology $(n=1)$ courses were willing to participate in an interview. This response rate might be explained by the fact that teachers at the university under study work on a part-time basis for distance learning courses and therefore other responsibilities might have inhibited their participation in this study. In addition, teachers' employment contracts do not foresee any contributions to research activities. It is acknowledged that the interview sample was relatively small and self-selected, and thus accompanied by the obvious potential biases. It is also noted that participating teachers may be individuals who consider themselves as 'technology-savvy', or particularly interested in using PLA in their practice, or even sceptical teachers with strong opinions as to how best to support learners. Therefore, any interest in using OUA (see "Thematic analysis" section) should be analysed considering for the above factor and its possible impact on teachers' perceptions about PLA use. A more representative sample selection would enable us to collect and compare the perspectives of teachers who are/are not technology enthusiastic and are/are not particularly interested in OUA, resulting in a multidimensional understanding of how and why OUA is used in the teaching practice. Insights should be treated as preliminary, and beginning to shed light on PLA adoption in higher education.

Yet, the in-depth nature of interviewing allowed us to identify and report the perceptions of participating teachers about the use of OUA in their practice. Interviews were conducted by the first author who had no prior involvement in the respective courses to minimize biases. All six interviewees chose to have a Skype interview. Oral informed consent was gained prior to the initiation of the interview by all interviewees. Interviews lasted between 25 and 45 min.

An interview protocol was devised and piloted prior to the interviews. Interview questions were open-ended and aimed to detail the experiences and perceptions of teachers 
about OUA. In addition, we hypothesized that TAM and ARM could potentially explain teachers' practices and, in particular, why some teachers adopted and used OUA whereas some others not. Therefore, we also added questions about issues such as easy of using OUA, perceived OUA effectiveness, feelings towards OUA and future intentions (as described in the two models). Interview questions were organised in the following four pillars (see Table 2): (1) teachers' background, (2) the impact of OUA on teaching, (3) teachers' concerns and feelings about OUA, and (4) future use and intentions. Apart from capturing the impact of OUA on teaching, the second set of questions (see (2) above) aimed to identify how TAM may relate to teaching practice. Similarly, the third and fourth set of questions (see (3) and (4) above) aimed to identify whether and how ARM may relate to OUA usage.

Interview data were entered to the NVivo software. Thematic analysis (Kvale 1996) was used to identify emerging themes related to the aims of this study, including the actual use of OUA by teachers, specific interventions towards students at risk, teachers' perceptions of use, and factors explaining usage (see Table 3). The first author, who was not previously involved in OUA activities with teachers, coded the first interview, which was then independently coded and analysed by the second author to ensure inter-rater reliability. The inter-rater percentage agreement, which equalled to $90 \%$, was calculated by dividing the number of times both researchers agreed by the total number of times coding was possible (Boyatzis 1998). Areas of disagreement referred to renaming codes to enhance comprehension and splitting one code into two sub-categories. Agreement was reached between the two coders and changes were fed into the coding of the rest of the transcripts. The final coding scheme and analyses were conducted by the first author. The third author who was involved in delivering OUA training sessions to teachers, was not involved in determining the final list of themes, yet he reviewed drafts of the analysis and improved the interpretation of the outcomes by providing contextual information related to teachers and their practice. Figure 6 presents the times per week each interviewee accessed the OUA dashboard. These data were discussed in the interview analysis (see "Phase 2: qualitative experiences of teachers using OUA" section).

\section{Results}

\section{Phase 1: quantitative impact of OUA on students' performance}

Tables 4 and 5 present descriptive statistics about the continuous and categorical variables entered in the model, including the two dependent variables (pass and completion). In categorical variables with more than two options (see Table 5), reference categories were mixed race, postgraduate qualification, and Health Care.

In relation to RQ1, two binary logistic regression analyses were performed with dependent variables completion and pass indicators. In terms of completion, a test of the full model against a constant only model was statistically significant, indicating that the predictors as a set reliably distinguished between students who complete and students who do not complete a course $\left(X^{2}(24)=80.84, p<.001\right)$. Nagelkerke's $R^{2}$ of .181 indicated a moderately weak relationship between prediction and grouping (18\% of variance explained by the proposed model in completion rates). Prediction success overall was $72.9 \%$ (25.4\% for not completing a course and $92.4 \%$ for completing a course). The Wald criterion demonstrated that only OUA weekly usage $(p=.003)$ and students' best previous course score $(p=.003)$ 


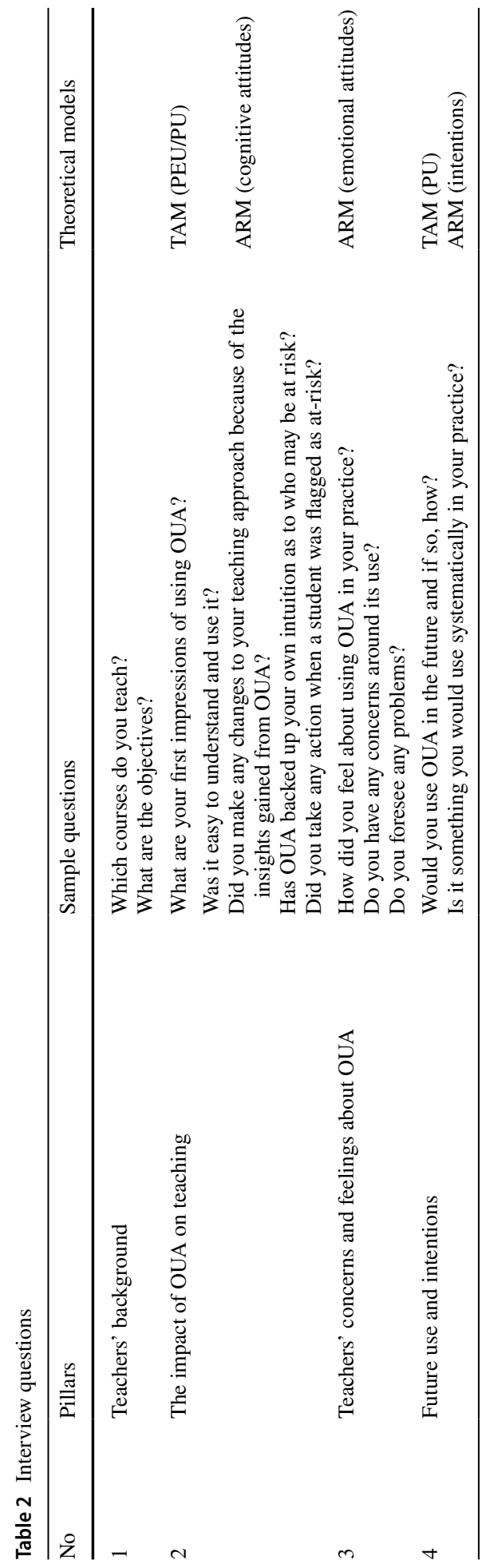


Table 3 Emerging themes identified through thematic analysis

\begin{tabular}{ll}
\hline Emerging themes & $\begin{array}{l}\text { Sub-categories of themes } \\
\text { OUA features }\end{array}$ \\
$\begin{array}{ll}\text { Features of the OUA dashboard that are used by teachers } \\
\text { Frequency of use } \\
\text { Ease of use } \\
\text { Teachers' perceptions of OUA as being useful or not }\end{array}$ \\
Perceived usefulness of OUA & $\begin{array}{l}\text { In what respect OUA supports teaching practices } \\
\text { How teachers react to students flagged as being at risk } \\
\text { What intervention strategies they devise to support students }\end{array}$ \\
Informing learning design & $\begin{array}{l}\text { How OUA could be used to inform the design of a course } \\
\text { Teachers' suggestions for improving OUA }\end{array}$ \\
Intention to use OUA in the future & Teachers' intentions to use OUA in the future
\end{tabular}

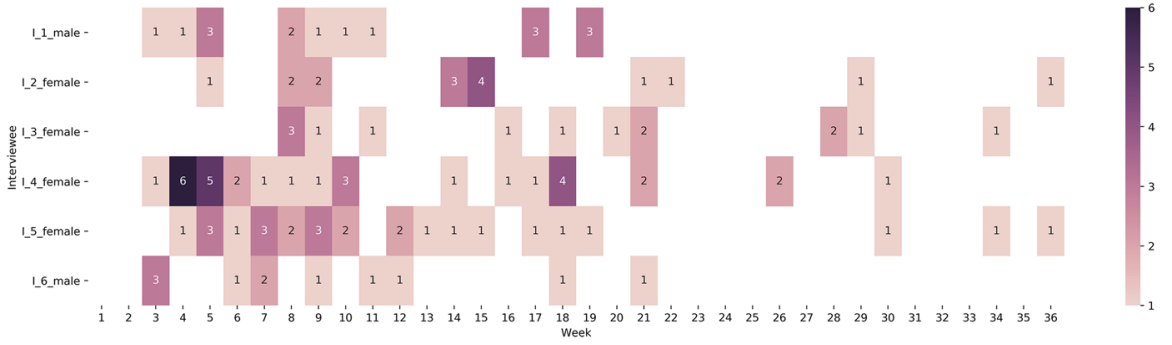

Fig. 6 Number of times per week each interviewee accessed the OUA dashboard. $X$ axis indicates the respective week of the term for participating courses. $Y$ axis indicates individual interviewees $(n=6)$

made a significant contribution to prediction. All other predictors were not significant. To evaluate the performance of the classification for completion, the Area Under the ROC Curve was examined. This was statistically significant and calculated as $.737(p<.001)$, suggesting that the accuracy of the proposed classification is fair or acceptable.

In terms of effect size, the odds ratio was examined. Exp (B) value indicates that when OUA usage is raised by one unit, that is a teacher is accessing OUA .1 or 10\% more of the duration of the course weeks, the odds ratio is 7,4 times as large and therefore students are 7,4 times more likely to complete the course (see Table 6). These findings indicate that increasing engagement with OUA predictions and greater best overall previous score were associated with an increase in the likelihood of completing a course. It is yet noted that a low percentage of prediction suggests that additional variables are likely to explain variability in the outcome variable. One such variable may be the teacher's general engagement with students (i.e., interactions to provide support, resolve questions). For example, a proactive teacher who does not make use of OUA may have students with better performance outcomes compared to teachers that are less supportive and systematically engaged with students.

In terms of passing the course, a similar picture was revealed $\left(X^{2}(24)=84.83\right.$, $p<.001)$. Nagelkerke's $R^{2}$ of .177 indicated a moderately weak relationship between prediction and grouping. The model explains $18 \%$ of the variance in passing rates and correctly classified over $69 \%$ of the cases. In particular, prediction success overall was 


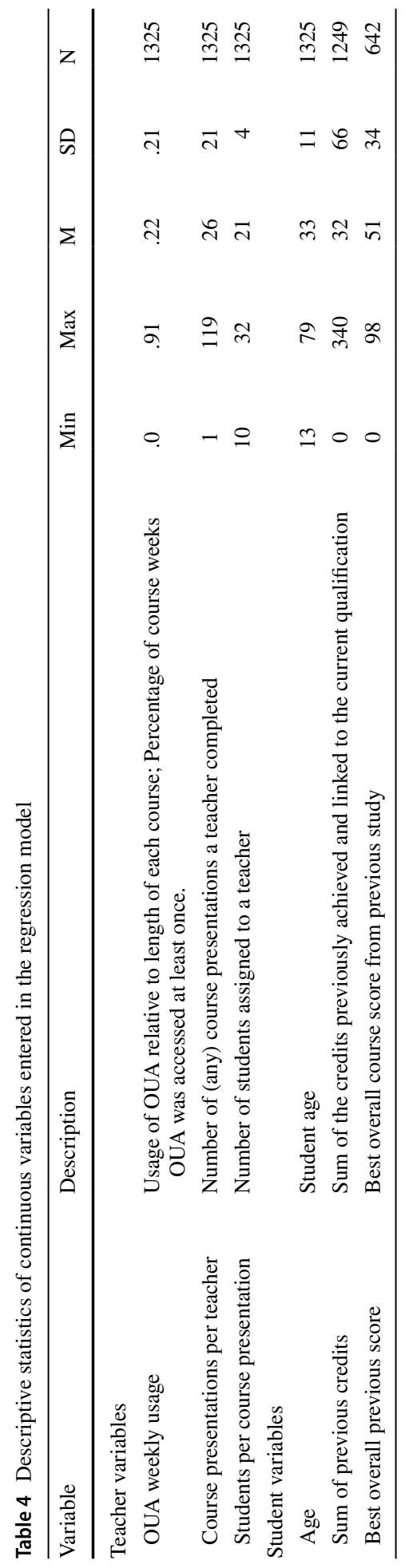


Table 5 Descriptive statistics (\%) for categorical data entered in the regression model

\begin{tabular}{|c|c|c|}
\hline \multicolumn{3}{|l|}{ Pass rates } \\
\hline Passed & 802 & $60.5 \%$ \\
\hline Failed & 523 & $39.5 \%$ \\
\hline Total & 1325 & $100 \%$ \\
\hline \multicolumn{3}{|l|}{ Completion rates } \\
\hline Completion & & $63.8 \%$ \\
\hline Non-completion & & $28.9 \%$ \\
\hline Total & 1325 & $100 \%$ \\
\hline \multicolumn{3}{|l|}{ Gender } \\
\hline Male & & $53.7 \%$ \\
\hline Female & & $46.3 \%$ \\
\hline Total & 1325 & $100 \%$ \\
\hline \multicolumn{3}{|l|}{ Disability } \\
\hline Yes & & $17.5 \%$ \\
\hline No & & $82.5 \%$ \\
\hline Total & 1325 & $100 \%$ \\
\hline \multicolumn{3}{|l|}{ Ethnicity } \\
\hline Asian & & $4.5 \%$ \\
\hline Black & & $3.9 \%$ \\
\hline Mixed & & $2.2 \%$ \\
\hline White & & $86.9 \%$ \\
\hline Total & 1325 & $100 \%$ \\
\hline
\end{tabular}

Qualifications

A Level or Equivalent to two A levels

HE qualification.

Lower than A level

No formal qualification

Postgraduate qualification

Missing

Total

IMD band

$0-25 \%$

25-50\%

50-75\%

75-100\%

Total

New/continuous

New

Continuous

Total

1325

1325

$45.1 \%$

$13 \%$

$36.5 \%$

$2.9 \%$

$2.3 \%$

$0.2 \%$

$100 \%$

$22 \%$

$26.3 \%$

$24.5 \%$

$23.2 \%$

$1274 \quad 100 \%$

Courses

Arts

Social science

Education

Health care

$1.8 \%$

Maths

Engineering
$14 \%$

$54.8 \%$

$45.2 \%$

$100 \%$

$11.5 \%$ 
Table 5 (continued)

\begin{tabular}{ll}
\hline Technology (2015) & $18 \%$ \\
Technology (2016) & $7 \%$ \\
Law & $18.6 \%$ \\
Total & 1325 \\
\hline
\end{tabular}

Table 6 Logistic regression model estimating effects of independent variables on completion $(\mathrm{N}=1325)$

\begin{tabular}{lrrrrr}
\hline Variable & \multicolumn{1}{c}{$\mathrm{B}$} & \multicolumn{1}{c}{ SE } & Wald & $p$ value & Exp(B) \\
\hline OUA weekly usage & 1.998 & .667 & 8.987 & $.003 *$ & 7.377 \\
Couse presentations per teacher & .003 & .006 & .315 & .575 & 1.003 \\
Students per course presentation & -.016 & .027 & .349 & .554 & .984 \\
Age & .010 & .010 & .916 & .339 & 1.010 \\
Disability & .000 & .000 & 2.389 & .122 & 1.000 \\
Sum of previous credits & .004 & .002 & 2.456 & .117 & 1.004 \\
Best overall previous score & .012 & .004 & 8.808 & $.003 *$ & 1.012 \\
New & -.545 & .374 & 2.130 & .144 & .580 \\
Gender & -.098 & .233 & .178 & .673 & .906 \\
Arts & -.749 & 1.199 & .391 & .532 & .473 \\
Social science & -.547 & 1.240 & .195 & .659 & .579 \\
Maths & -.213 & 1.153 & .034 & .854 & .808 \\
Engineering & -.953 & 1.179 & .653 & .419 & .386 \\
Technology (× presentations) & -.973 & 1.170 & .692 & .406 & .378 \\
Law & .071 & 1.154 & .004 & .951 & 1.074 \\
Education course & .117 & 1.159 & .010 & .920 & 1.124 \\
Ethnicity Asian & 1.026 & .938 & 1.199 & .274 & 2.791 \\
Ethnicity Black & -.667 & .741 & .810 & .368 & .513 \\
Ethnicity White & -.356 & .618 & .331 & .565 & .701 \\
IMD band & .063 & .092 & .463 & .496 & 1.065 \\
A Level or Equiv. & 1.161 & .684 & 2.883 & .090 & 3.193 \\
No formal qualification & -.162 & .842 & .037 & .847 & .850 \\
HE qualification & 1.049 & .706 & 2.208 & .137 & 2.856 \\
Lower than A level & .671 & .678 & .978 & .323 & 1.956 \\
(constant) & -.112 & 1.618 & .005 & .945 & .894 \\
\hline & & & & &
\end{tabular}

Model $\chi^{2}=80.84, d f=24, p<.001$

69.5\% (35.5\% for not passing a course and $87.6 \%$ for passing a course). The Wald criterion demonstrated that only OUA weekly usage $(p=.001)$ and students' best previous course score $(p=.001)$ made a significant contribution to prediction. Odds ratio value indicated that when OUA usage is raised by one unit, the odds ratio is 7.5 times as large and therefore students are 7.5 times more likely to pass the course (see Table 7). In line with existing studies suggesting that the instructor's role (e.g., Arbaugh 2014; Ma et al. 2015) and students' success in previous courses (e.g., Hachey et al. 2014) are predicting performance, these findings indicate that the increasing engagement of teachers with OUA predictions along with the students' greater best overall previous score are associated with an increase in the likelihood of passing a course. To evaluate the performance 
Table 7 Logistic regression model estimating effects of independent variables on pass rates $(\mathrm{N}=1325)$

\begin{tabular}{lrrrrr}
\hline Variable & \multicolumn{1}{c}{ B } & \multicolumn{1}{c}{ S.E. } & Wald & $p$ value & Exp(B) \\
\hline OUA weekly usage & 2.010 & .617 & 10.595 & $.001 *$ & 7.461 \\
Couse presentations per teacher & .002 & .005 & .111 & .739 & 1.002 \\
Students per course presentation & .002 & .026 & .008 & .928 & 1.002 \\
Age & .009 & .009 & .932 & .334 & 1.009 \\
Disability & .000 & .000 & 3.067 & .080 & 1.000 \\
Sum of previous credits & .002 & .002 & .865 & .352 & 1.002 \\
Best overall previous score & .012 & .004 & 10.084 & $.001 *$ & 1.012 \\
New/continuous & -.740 & .369 & 4.029 & .045 & .477 \\
Gender & -.191 & .220 & .750 & .386 & .826 \\
Arts & -1.110 & 1.180 & .884 & .347 & .330 \\
Social science & -.300 & 1.212 & .061 & .805 & .741 \\
Maths & -.272 & 1.144 & .057 & .812 & .762 \\
Engineering & -1.007 & 1.170 & .741 & .389 & .365 \\
Technology (× presentations) & -1.720 & 1.158 & 2.207 & .137 & .179 \\
Law & -.113 & 1.144 & .010 & .921 & .893 \\
Education course & -.292 & 1.145 & .065 & .799 & .747 \\
Ethnicity Asian & .912 & .842 & 1.174 & .278 & 2.490 \\
Ethnicity Black & -.317 & .699 & .206 & .650 & .728 \\
Ethnicity White & -.287 & .569 & .255 & .614 & .750 \\
IMD band & .024 & .086 & .076 & .783 & 1.024 \\
A Levels or Equiv. & 1.158 & .617 & 3.518 & .061 & 3.183 \\
No formal qualification & .249 & .796 & .098 & .754 & 1.283 \\
HE qualification & 1.132 & .637 & 3.160 & .075 & 3.102 \\
Lower than A level & .745 & .614 & 1.474 & .225 & 2.107 \\
(constant) & -.205 & 1.553 & .017 & .895 & .814 \\
\hline
\end{tabular}

Model $\chi^{2}=84.83, d f=24, p<.001$

of the classification (passing), the area under the ROC Curve was examined. This was statistically significant and calculated as .724 $(p<.001)$, suggesting that the accuracy of the proposed classification is fair or acceptable.

The following examples of students exemplify further the outcomes of the regression analysis: (a) Low OUA usage_Low previous performance: "Student 857" is female, 41 years old, attending an education course. Her previous best score is $14 \%$ and her teacher accessed OUA $2 \%$ of the weeks of the course (approx. 1 week out of 40 ). This student is more likely to fail their studies as both predictors of performance are relatively low. (b) High OUA usage-Low previous performance: "Student 869 " is female, 34 years old attending an education course. Her teacher has accessed OUA $46 \%$ of the weeks of the course (approx. 16 weeks out of 40) and her previous best score is $28 \%$. Despite the low previous score, this student may complete and pass their studies given the teacher's usage of OUA. 


\section{Phase 2: qualitative experiences of teachers using OUA}

\section{Access to OUA dashboard}

In order to address RQ2 and RQ3, we analysed data from six interviews with teachers who used OUA in their teaching practice. Figure 6 shows the times per week each of the six interviewees logged into the dashboard. The majority of the participating teachers did not access the dashboard regularly (i.e., every week when predictions were updated), yet they accessed it throughout a course presentation at selected weeks. Some of them were found to be more active in the first few weeks of the course, in particular, interviewees 1, 4 and 5 , who logged in the dashboard more than once per week. Logging in activity was found to decline after the first few weeks of a course presentation. The selected use of the dashboard might suggest that teachers chose to check OUA data at certain points, such as near an assignment submission week (i.e., 4-6 times per course). This infrequent access to OUA data by teachers might have limited the potential effectiveness of OUA interventions.

\section{Thematic analysis}

OUA features The two main functions teachers found more interesting and helpful when they made use of the OUA dashboard were the OUA colour-coded system indicating students "at risk" (i.e., Fig. 3) and students' activity in the VLE (i.e., Fig. 2). Interviewed teachers mostly gave attention to students who were flagged as red or amber rather than those flagged as green (indicating no risk). However, one teacher indicated that: "I found it quite encouraging to look at the ones who are doing well and then sending emails and encouraging those [...] it's quite a good tool to use on both ends of the spectrum" (Interviewee 1, male). In addition, the level of the VLE activity comprised a major indicator of whether students were engaged with the course, the materials, and whether they will submit their next assignment. As explained by Interviewee 2:

"I just drill down to my students and look through for the red [...] I won't look at the nearest neighbour or anything like that. I generally just have a look at how much they've been interacting on the VLE and with the website" (Interviewee 2, female).

From the teacher analytics data, teachers were found to access OUA rarely usually before the submission of an assignment. Interviewed teachers stressed the voluntary nature of their interaction with OUA and the fact that they could individually determine whether using OUA would be time-consuming or not. The below excerpt also points to the easy of using the system- “a quick glance" would suffice to identify students at risk (see also another reference by Interviewee 2 "I think it's quite straightforward"):

"I think that would depend on how many students were at risk. I think it could be time consuming but I think it's as time consuming, as you want it to be perhaps [...]. You could use it as a quick glance or you could spend a lot of 'me drilling down and having a look at particular students" (Interviewee 2, female).

Overall, the type of interaction with OUA was found to vary and be rather limited to specific features of OUA. Specifically, teachers were those deciding how and what features of OUA to use, including the colour-coded system and the VLE activity. Other system features, such as the nearest student functionality, indicating how a student's 
performance approaches or deviates from others in different course presentations, were not used by teachers. In contrast, OUA was perceived as easy to use and straightforward (see also "Improvements and intention to use OUA in the future", suggestions for changes were unrelated to the easy of using OUA). An interesting contradiction is highlighted when participants' consistently strong ease-of-use is considered alongside their varied ways of engaging with OUA features. While the ease-of-use condition proposed by TAM for "technology acceptance" appears to have been met, it appears that users' perceptions of easeof-use were formed in referenced to different functions, with some interviewees accessing only specific features of the system and avoiding others.

Usefulness of OUA Participating teachers perceived OUA as a very useful tool for a range of reasons that often related to existing teaching practices and expertise. For participants who tended to check on their students often, either through sending emails, or checking the forums for students' activity, OUA provided a useful tool that systematized these practices, and made it easier to identify what students were doing at certain times. For other participants, OUA influenced their teaching practices by making them more proactive in contacting students when needed and being "on top" of what students were doing at a given moment. Participating teachers found OUA particularly useful in between the submission of their assignments, especially for those students who did not engage with forums or online activities. It could be argued that teachers' cognitive evaluations of OUA were very positive, pointing to low levers of academic resistance, as explained by $\mathrm{AR}$, and in relation to the cognitive dimension of attitudes.

As evidenced previously, many groups of students may not be engaged with discussion forums in terms of posting, but they do read and reflect on contributions by peers (Macfadyen and Dawson 2010; Mazzolini and Maddison 2003; Romero et al. 2013). These "ghost" students were relatively invisible to teachers. OUA provided some insights into their engagement behaviour. This early indicator of students' activity could prevent a possible non-submission of an assignment as teachers were more inclined to intervene and support a given student. OUA provided an indication as to when a teacher should intervene and, as explained by a teacher, "where I need to put my efforts" (Interviewee 6, male). OUA was perceived as a tool that complemented existing teaching practices, such as contacting students and checking their activities online. As explained by teachers:

"I love it. [...] It brings together the things that I would normally do so if I haven't heard from a student then I will often have a look to see when they were last online or have a look see if they're getting involved on the forums" (Interviewee 2, female). "One of the things that the OUA a hundred per cent has been made me do is being much more proactive in sending out messages around in between assignments group messages [...] I sort of feel that I am on top of what the students are doing" (Interviewee 5, female).

The OUA predictions as to who might be at-risk of not submitting their next assignment aligned well with the teachers' own assumptions of who might be at-risk. Yet, in some cases OUA provided additional insights as a teacher might have not identified a student as being at-risk without the support of OUA. In addition, the role of the teachers in interpreting OUA predictions was crucial. As was previously found (Dyckhoff et al. 2012; van Leeuwen et al. 2014), teachers were aware of the nature and particularities of each course and were able to judge whether a student "at risk" as predicted by OUA required further attendance or not: 
“I might be worried about a student because I haven't heard from them whereas OUA can tell me that they've been getting involved and that it's quite likely that they will be okay. [...] it generally just confirms my suspicions but with those two cases I had no idea" (Interviewee 2, female).

"I don't think that it is always going to be right. I think that with the nature of this particular course [maths] people can work offline. [...] But then it's down to me and my opinion to look into it and see if it is right" (Interviewee 2, female).

While generally teachers' perceptions of OUA usefulness seem to relate to actual uses, the following excerpts present a contradiction. Interviewee 2 perceived OUA as "not indepth", while Interviewee 1 stressed a need for a better understanding of the usefulness of OUA after becoming engaged with additional features, suggesting that a more in-depth understanding of OUA might more likely lead to better and more effective use. These two interviewees share a relatively similar pattern of OUA usage, suggesting that greater perceived usefulness of OUA may not relate to greater actual use or "technology acceptance", as TAM advocates. Yet, this is a tentative interpretation as differences between interviewees in relation to the amount of time they spend on OUA and the features they access-not captured in the current study-may explain this contradiction.

"I think it's quite straightforward. But it's not in depth for the things I use it for. I mean I can just go on and look at my students see if they are "at risk" and drill down. There's not a lot to use really from my point of view" (Interviewee 2, female).

"The more experience you have of using it the more you understand how valuable it is and how you can use it for your particular cohorts[...] I did have a look at such things gender and qualifications to see if that made a deference in with the way that they were actually working. [...]it's not a steep learning curve" (Interviewee 1, male).

The discussion in this section also points to the emotional attitudes of teachers, as explained by AR, in particular their positive feelings and emotions when using OUA for supporting students. Yet, a form of ambivalence between cognitive and emotional attitudes is observed; the varied patterns of OUA use (see "OUA features" section) indicate a variation in cognitive beliefs, in relation to which features of the system are accessed and perceived as useful. This variation comes to contrast with consistently positive emotional attitudes, and may suggest that interviewees choose to access those features of OUA they feel comfortable with, rather than features they do not understand well, or they are challenging, and that could cause negative perceptions about the system.

Approaching students at risk In line with previous research (Ali et al. 2013; Hanson 2009; Herodotou et al. 2019; van Leeuwen et al. 2014), teachers were found to adopt different approaches when a student was flagged as being at-risk, including a referral to student support services, sending an email, texting, calling, or doing nothing (as they were aware of why a student is offline). For some teachers, referral to student support services was the first and straightforward option, yet it did involve additional work:

"I was flagging them up to student support services and it was an extra lot of work" (Interviewee 5, female).

Other teachers chose to send an email, give a call or text students. The reasons behind a given choice varied. The following two excerpts indicated that teachers have different perceptions as to what the best way of reaching students might be: 
"I start off with a couple of emails because I find most students prefer email contact but they haven't replied and then I do follow up with a phone call" (Interviewee 4 , female).

"I prefer to give them a call because I think the highest level of communication you can get is the best one. If you speak to someone you can read a lot more from their voice" (Interviewee 2, female).

Reaching students was not always successful. Some teachers faced challenges due to students not replying to emails, calls, or texts. In such cases, teachers made a reference to students support services. As explained by a teacher: "It sorts of ties in quite well with the support - the student support system [...][they] can obviously chase up the students from a novel angle" (Interviewee 1, male). Overall, it remains unclear which intervention strategy may be the most effective one in order to motivate and support students "at risk" and potentially help them complete and pass their studies.

These insights point to an underlying variation in terms of teaching approaches and perceptions of what the teachers' role might actually be (Hanson 2009; Mazzolini and Maddison 2003; Norton et al. 2005; Rienties et al. 2013). Some teachers seemed very persistent in reaching out to students, while others were less pro-active or persistent. Others perceived a referral as the action to be taken forward when a student was flagged at risk. These differences became more apparent when teachers were asked to describe how they perceived their teaching role in the course they taught. As explained:

"I find a lot of my time is spent encouraging the lesser able students rather than engaging with the better students to improve their approach to their studies and things. It's about maintaining people on the course so that they can have a chance of progressing to the next level" (Interviewee 6, male).

The ways teachers checked on their students' performance varied in terms of persistency, pro-activeness, and sources of information accessed. The following excerpts point to persistent teachers who checked on students regularly:

"I kept looking at their contact history, one of them again I could see nothing [...] but I say okay I will do it one more time. I contacted them. No answer. Left a voice message for them. That was lost now. Again, I emailed them. Lost now. So far nothing" (Interviewee 3, female).

" if I haven't had contact from a student I'll search around on the website and see if they are getting engaged in other ways like in the forums or when they last logged in but that's about all I have normally whereas with OU Analyse you can see how much they are getting involved" (Interviewee 2, female).

Informing learning design Teachers made suggestions as to how information from OUA could be used to inform the design of their courses, such as the addition of activities to boost students' motivation:

"If it looked like people were losing motivation at a certain point I would probably try and get an online tutorial together to check on everybody" (Interviewee 2, female).

"quite often we lose them between the second and third TMA or the third and fourth TMA so I don't know if this highlights the need to find some way to engage them better between TMAs" (Interviewee 4, female). 
Yet others perceived the use of OUA as of help to the teacher per se and not relevant to improving content:

"It's just being in touch with the student and picking up the student at earlier stage [...]. to my knowledge, it won't help in the content - the course" (Interviewee 3, female).

Improvements and intention to use OUA in the future Teachers would like OUA to become more "sensitive" and provide information as to what students were engaged with at certain times in the VLE, such as which course activities they work on. As explained:

"If it was more sensitive to what students were accessing or what they were doing in terms of their literacy and numeracy skills [...] I think it could probably influence my teaching and my practise"(Interviewee 5, female).

Teachers asked for improvements in what information can be recorded by teachers in OUA, such as their own outstanding actions (e.g., follow-up students who have not replied) and accessing OUA information through a single teacher portal to minimise workload. One teacher who devised her own strategy to monitoring students' progress using excel sheets explained:

"what I do when I get my first batch of students I download the students' names into a spreadsheet and from there I add columns so I can record who has done their TMA, who was doing the group activity etc. Because now OUA was doing some of that for me I can add actions and updates. I think if that could be developed further I think that could replace the need for me to keep a separate spreadsheet" (Interviewee 4, female).

The proposed changes above could be viewed as manifestations of teachers' cognitive resistance to using OUA at its current form, which when waived away, could facilitate adoption, and potentially encourage more systematic usage. These cognitive beliefs are also in contrast to teachers' intention to using OUA in the future; although a considerable interest for future use was recorded, teachers raised concerns in relation to some of its functionality that might inhibit use, such as being sensitive to students' specific actions online:

"I think I've now got to grips with it and when some changes were made I will be

very interested in using it again. Very supportive of it" (Interviewee 5, female).

In terms of academic resistance, as explained by AR, participating teachers expressed positive emotional and intentional attitudes about OUA, yet these were in contrast to their cognitive beliefs and the inconsistency observed in relation to OUA features they choose to use and find useful as well as their suggested changes to the system.

\section{Discussion}

In this multi-method study, we described and explored a university-wide implementation of PLA in a distance learning higher education institution in which 59 teachers and 1325 students from nine courses participated. Participating teachers were granted access to PLA data produced weekly by OUA, a system designed to predict students "at risk" of not 
submitting their next assignment. Whether and how predictive data should be used was up to the teachers to decide along with the identification of an intervention strategy to support students flagged as being at risk.

In our multi-method approach, we first explored the quantitative impact of teachers' use of OUA on students' performance. With regards to the extent to which OUA usage by teachers predicts students' performance (RQ1), binary logistic regression analysis with student, course, and teacher variables as predictors revealed that engagement with and usage of OUA, along with the students' success in previous courses, positively predict students' pass and completion performance. The more teachers make use of OUA data and the more successful students were in previous courses, the likelihood of completing and passing a course increases. These findings emphasise that, in addition to previous student performance, teachers play a crucial role in online learning settings. While other studies emphasised aspects of teaching such as guidance and assistance for completing online activities (Ma et al. 2015) or teaching presence as perceived by students (Arbaugh 2014), this study revealed how usage of a predictive system, OUA can contribute positively to students' performance. At the same time, as indicated by the user statistics of OUA, many teachers seemed reluctant to frequently engage with the system on a weekly basis.

These findings are significant as they are starting to shed light on our rather limited understanding of how teachers' usage of learning analytics may relate to student performance. Existing studies presenting mixed effects (van Leeuwen et al. 2015, p. 28), captured teachers' perceptions of analytics in experimental set ups, rather than in naturalistic settings, and in a relatively short period of time. In contrast, in the present study participating teachers were given access to "live" student data and their participation was monitored over the duration of a course presentation (long term). These methodological differences may explain why the present study have reached more conclusive outcomes whereas previous studies have not.

Yet, any causal interpretation of the above findings should be treated with caution, as additional variables, not captured in the regression analysis may have had an influence or explain student learning outcomes. For example, teachers who are more engaged with their students (i.e., interactions to provide support, resolve questions) may have students with better learning outcomes compared to teachers that are less supportive and engaged with students (Herodotou et al. 2019). These teachers may well be those actively using OUA, and this may be a factor mediating the relationship between OUA usage and learning outcomes. Future studies should examine in particular whether PLA-guided support to students is more effective than less data-intensive approaches such as accessing student information hosted in the University's management system (e.g., last student log in date, demographics, TMA score and submission). Towards this direction, Herodotou et al. (2019) identified that teachers with relatively low or no usage of OUA had worse performing students than teachers with high usage of the system. Also, teachers with average OUA use had better performing students when using the system, than the year before when they had no access to OUA (and after controlling for variation in student performance characteristics). These findings suggest that PLA-guided support is actually significantly better than other less-data intense support approaches devised by teachers. Similarly, the actual design of different courses (level of difficulty of course material, assessment points etc.) may have had an impact on students' engagement with the material affecting the chances of completing and passing their courses. Also, the actions teachers have or have not taken in response to OUA insights may also relate to student learning outcomes as they may have facilitated learning or empowered learners to reach course completion. 
Another aspect that should be considered in interpreting these outcomes is the number of teachers participating in the study $(\mathrm{N}=59)$ and the mean OUA engagement $(M=.22$; Max =.91). A further examination of the distribution of OUA usage across teachers showed that the median of use was .13, suggesting that half of the teachers had rather limited access to the system. Therefore, it is likely that a relatively small number of teachers who demonstrated intensive usage had an outsized impact on the analysis, explaining the high coefficient of OUA usage in the regression models.

In Phase 2, we explored the experiences of teachers who made use of OUA to improve our understanding of why some teachers were actively using OUA in their practice, while others teachers were perhaps reluctant to embrace the system. With regards to the extent to which participating teachers made use of OUA data and visualisations to help students "at risk" (RQ2) and the factors that explain teachers' use of OUA (RQ3), six semi-structured interviews with teachers-volunteers were conducted building on the theoretical lenses of TAM (Davis 1989) and ARM (Piderit 2000). Insights revealed how OUA was used and in what degree. In line with Perceived Usefulness of TAM (Davis 1989; Sanchez-Franco 2010), teachers reported to make use of specific features of OUA only, including the colour-coded system and the VLE activity. The OUA teacher usage data indicated that most teachers used OUA rather infrequently, primarily for a short period of time just before the submission of an assignment. In terms of the use of the 'risk indicators', teachers reported that the predictions reaffirmed their suspicions about who might be at risk. Yet, in some cases, OUA predictions provided additional insights a teacher might not have identified without the support of the system. In terms of perceived ease of use (Davis 1989; Rienties et al. 2016), teachers found OUA simple to use, faced no obstacles when accessing data, and view the tool as not being time-consuming.

OUA was perceived by teachers as either complementing existing student monitoring practices or influencing proactive engagement with students. For teachers used to checking on students and their progress often, it systematised their practices and made it easier to identify what students were doing at certain times. For others, it influenced their practices positively by making them more proactive in contacting students when there was a need and illuminated students' activity in between the submission of assignments, especially for those students who did not engage with e.g., forums or other online activities. It could be argued that, even though the perceived usefulness of OUA was subjectively defined, teachers were not reluctant to use OUA and they found value in its use as complementing their own existing practices or empowering them to become more proactive with students (RQ3).

A variation was observed in terms of the type of intervention strategy teachers adopted to support students at-risk and their level of persistence in reaching students. Each teacher devised their own approach, including making a phone call, sending an email, or referring the student to support services. Yet, it remains unclear which intervention strategy was the most effective one in order to support students "at risk" and potentially help them complete and pass their studies (Rienties et al. 2016; van Leeuwen et al. 2014). This is the focus of follow-up studies that take place at the university under study at the moment; a number of different intervention strategies are piloted to identify which of them effectively supports 'at-risk' students.

Overall, teachers expressed interest in using OUA in the future to better support students "at risk" and improve the design of the courses they are teaching by, for example, designing additional activities when engagement between assignments tails off. In relation to RQ3, academic resistance, as conceptualised by (Piderit 2000), towards the use of analytics to support teaching activities was shown to relate to cognitive beliefs, in particular 
teachers' inconsistency in terms of which features of OUA they access and perceive as useful, as well as certain enhancements to the system that could facilitate adoption. Emotional and intentional aspects of resistance were shown to align with teachers expressing positive feeling about OUA and declaring their intention to use it in the future. It is noted that teachers in this study were self-selected, with obvious self-selection limitations. A large number of teachers seemed to vote with their feet by not engaging with OUA at all or only close to the assessment deadlines. Previous studies have highlighted that the time window of opportunity to effectively support students at-risk is relatively short (Gasevic et al. 2016; Tempelaar et al. 2015), ranging between 2 and 4 weeks.

A paradox is observed between the teachers' perceptions about the usefulness of OUA and their actual, rather infrequent use of the system. Although the use of OUA was an optional activity for teachers, Figs. 5 and 6 show evidence of lack of regular use and ongoing engagement with it. Briefing online sessions about what PLA are, what tools are available, and how they could be used to support the teaching practice were organised and offered to participating teachers before the start of their courses. While teachers were aware of the sessions well in advance, actual participation was very limited in the range of 5-6\%. This lack of interest and motivation in using OUA should be examined considering for the teachers' contractual agreement with the university and the conditions under which they teach. Teachers do not hold permanent positions within the university; they are contracted employees whose contracts renew on a yearly basis. The great majority of them are parttime employees and teaching is not their primary source of income as they usually hold other full-time positions. These conditions may relate to viewing themselves as temporary staff of the university for whom professional development is not essential. In addition, teachers' contracts do not foresee participation in OUA, or other relevant activities, raising additional barriers to participation.

The lack of interest in engaging or adopting OUA may also relate to other factors such as limited time availability to engage with extracurricular, professional development activities, teachers' 'trust' to OUA data as opposed to directly communicating with students, and teachers' lack of competency in interpreting OUA insights and taking appropriate action. These considerations may also explain the above paradox; while expressing an interest in using OUA in the teaching practice, teachers made limited and rather infrequent use of it. Given the positive results of logistic regression analysis, it could be argued that usage of OUA by teachers would benefit students and lead to better learning outcomes. In addition to effective predictive analytics tools, a clear and supportive management and professional development structure needs to be in place to empower teachers to pro-actively help students flagged as "at risk" (Herodotou et al. 2019; Mor et al. 2015). Managerial arrangements should provide technical and pedagogical support to teachers when using OUA, offer teachers training as to how to use OUA on a yearly basis before and/or during a new course presentation, and set up a virtual space for sharing good practice around the use of OUA within the teaching community, raise and negotiate concerns and access relevant sources of information. Also, the use of OUA should be included in contractual agreements as a tool that can support students' learning and inform the teaching practice. Any requirements for additional professional development activities related to OUA should be compensated accordingly. 


\section{Conclusions}

This study about the use of OUA by 59 teachers and 1325 students at a distance learning higher education institution has illustrated teachers' actual uses and practices in relation to OUA data and indicated a variation in teachers' degree and quality of engagement with learning analytics. This variation was evidenced in how often predictive data were accessed, what predictive data teachers looked at and foremost, how teachers acted on this data to support students. Despite the lack of consensus, greater OUA usage was found to predict better completion and pass rates, suggesting that systematic engagement with OUA should become a significant aspect of the teaching practice as it can improve student performance.

Yet, this may not be a straightforward endeavour. What is required is teachers who are willing to use and act upon PLA data for the benefit of their students and of the teaching practice. This study highlights that, at this early stage of OUA development and diffusion in the teaching and learning practice, access to OUA did not result in systematic use of OUA. This finding has certain implications in terms of actions that facilitate OUA acceptance and best use including, for example, allowing time for teachers to engage with and understand the potential of PLA to support learning, designing easy to understand and use visualisations, and providing teachers with PLA features that are theoretically informed, unpack learning processes and highlight areas students struggle with. Towards this direction, the PLA system used in this study provides recommendations as to the content areas a student should engage with in order to cope with course requirements and submit their next assignment. Successful case-studies of PLA data use by teachers could work as a stepping stone for capturing the teachers' interest and diverting their efforts towards using PLA to support students in need. In addition, certain implementations of PLA could facilitate technology acceptance more than others. As interview data revealed in this study, PLA provided through the OUA dashboard were perceived as easy to use and useful by teachers, suggesting that OUA is a suitable PLA tool for use by teachers. Yet, further actions are needed to facilitate adoption, such as ongoing support and appropriate training in interpreting and effectively acting upon OUA data.

Moreover, findings from this study revealed that OUA was a significant source of information for teachers that can enhance and facilitate the teaching practice, especially within distance learning contexts where teacher-student interactions can be restricted (Mazzolini and Maddison 2003; Rienties et al. 2013; Simpson 2013). This finding has certain implications in terms of whether and how PLA tools could be used in the teaching practice; PLA tools can be particularly useful to teachers as they can alert them about students who may require special attention or support to proceed with their learning, enhance and complement teaching strategies, in particular, within distance learning contexts. Such insights could lead to proactive teaching practice; teachers approaching students flagged as at risk, discussing their progress and performance, identifying possible learning difficulties and providing 'real-time', tailored support to accommodate students' learning needs.

In addition, this study has implications relevant to the design of online courses; PLA insights could lead to 'live' or retrospective changes to a course. This may require adaptations or modifications of teaching activities or lesson plans to host the delivery of additional activities that can scaffold a specific cohort of students and address their learning needs. Alternatively, PLA could be used retrospectively to inform the design of a course such as spreading the workload evenly across weeks to ensure that students cope with requirements and manage to submit assignments on time. It may also entail guidance on 
how much time is needed to prepare an assignment, how to organise workload and prioritise activities to ensure that deadlines are met and assignments are delivered at the standards required.

While van Leeuwen et al. (2014) found a significant positive impact of providing learning analytics dashboards to teachers in a small-scale study of 20 teachers, additional research in large-scale settings across multiple courses and disciplines is needed to measure the impact of teachers' interventions on students' progress and retention. Findings from this study revealed a variation in intervention strategies devised by teachers to support students flagged as at risk, suggesting that more research is needed to identify how, when, and what interventions to trigger to adequately support students (Rienties et al. 2016; Torgerson and Torgerson 2008). For example, we need to understand whether we must intervene with a student as soon as they are flagged as "at risk" of not submitting an assignment, or wait for the next set of predictions before action is taken (Gasevic et al. 2016; Mor et al. 2015; van Leeuwen et al. 2015).

Towards this direction, we have set up the Early Alert Indicators project in order to examine the impact of specific intervention strategies on students' retention with teachers from 25 courses. The two-year project is expected to gather more evidence on the usefulness and effectiveness of using predictive data to support students. It will examine in particular how usage of OUA before an assignment deadline may relate to students' submitting (or not) the assignment on time and associated grades. To overcome the self-selecting bias, predictive data will be shared widely across courses by providing access to all teachers within a course. Also, it will make use of experimental methodologies including A/B testing and randomised control trials (RCTs) to evaluate the use of predictive data by teachers. Our overall objective is to identify best practice in the use of predictive data that will assist teachers to better understand PLA, devise appropriate intervention strategies, and engage students at-risk with learning prior to failing or not completing their studies.

\section{Compliance with ethical standards}

Conflict of interest The authors declare that they have no conflict of interest.

Open Access This article is distributed under the terms of the Creative Commons Attribution 4.0 International License (http://creativecommons.org/licenses/by/4.0/), which permits unrestricted use, distribution, and reproduction in any medium, provided you give appropriate credit to the original author(s) and the source, provide a link to the Creative Commons license, and indicate if changes were made.

\section{References}

Ajzen, I. (1991). The theory of planned behavior. Organizational Behavior and Human Decision Processes, 50(2), 179-211. https://doi.org/10.1016/0749-5978(91)90020-T.

Ali, L., Asadi, M., Gašević, D., Jovanović, J., \& Hatala, M. (2013). Factors influencing beliefs for adoption of a learning analytics tool: An empirical study. Computers \& Education, 62, 130-148. https://doi. org/10.1016/j.compedu.2012.10.023.

Ali, L., Hatala, M., Gašević, D., \& Jovanović, J. (2012). A qualitative evaluation of evolution of a learning analytics tool. Computers \& Education, 58(1), 470-489. https://doi.org/10.1016/j.compe du.2011.08.030.

Arbaugh, J. B. (2014). System, scholar, or students? Which most influences online MBA course effectiveness? Journal of Computer Assisted Learning, 30(4), 349-362. https://doi.org/10.1111/jcal.12048. 
Bodily, R., \& Verbert, K. (2017). Review of research on student-facing learning analytics dashboards and educational recommender systems. IEEE Transactions on Learning Technologies, 10(4), 405-418. https://doi.org/10.1109/TLT.2017.2740172.

Boyatzis, R. E. (1998). Transforming qualitative information: Thematic analysis and code development. Thousand Oaks: Sage.

Calvert, C. (2014). Developing a model and applications for probabilities of student success: A case study of predictive analytics. Open Learning: The Journal of Open, Distance and e-Learning, 29(2), 160-173. https://doi.org/10.1080/02680513.2014.931805.

Davis, F. D. (1989). Perceived usefulness, perceived ease of use, and user acceptance of information technology. MIS Quarterly, 13(3), 319-340.

Davis, F. D., Bagozzi, R. P., \& Warshaw, P. R. (1989). User acceptance of computer technology: A comparison of two theoretical models. Management Science, 35(8), 982-1002.

Dyckhoff, A. L., Zielke, D., Bültmann, M., Chatti, M. A., \& Schroeder, U. (2012). Design and implementation of a learning analytics toolkit for teachers. Journal of Educational Technology \& Society, 15(3), $58-76$.

Ferguson, R., \& Buckingham Shum, S. (2012). Social learning analytics: Five approaches. Paper presented at the 2nd International Conference on learning analytics and knowledge, Vancouver, British Columbia.

Gasevic, D., Dawson, S., Rogers, T., \& Gasevic, D. (2016). Learning analytics should not promote one size fits all: The effects of instructional conditions in predicating learning success. Internet and Higher Education, 28, 68-84. https://doi.org/10.1016/j.iheduc.2015.10.002.

Gasevic, D., Dawson, S., \& Siemens, G. (2015). Let's not forget: Learning analytics are about learning. TechTrends, 59(1), 64-71. https://doi.org/10.1007/s11528-014-0822-x.

Gliner, J. A., Morgan, G. A., \& Leech, N. L. (2011). Research methods in applied settings: An integrated approach to design and analysis. London: Routledge.

González-Torres, A., García-Peñalvo, F. J., \& Therón, R. (2013). Human-computer interaction in evolutionary visual software analytics. Computers in Human Behavior, 29(2), 486-495. https://doi. org/10.1016/j.chb.2012.01.013.

Greller, W., \& Drachsler, H. (2012). Translating learning into numbers: A generic framework for learning analytics. Journal of Educational Technology and Society, 15(3), 42.

Gutiérrez, F., Seipp, K., Ochoa, X., Chiluiza, K., Laet, T. De, \& Verbert, K. (2018). LADA: A learning analytics dashboard for academic advising. Computers in Human Behavior. https://doi.org/10.1016/j. chb.2018.12.004.

Hachey, A. C., Wladis, C. W., \& Conway, K. M. (2014). Do prior online course outcomes provide more information than G.P.A. alone in predicting subsequent online course grades and retention? An observational study at an urban community college. Computers \& Education, 72, 59-67. https://doi. org/10.1016/j.compedu.2013.10.012.

Hanson, J. (2009). Displaced but not replaced: The impact of e-learning on academic identities in higher education. Teaching in Higher Education, 14(5), 553-564. https://doi.org/10.1080/135625109031867 74.

Herodotou, C., Rienties, B., Boroowa, A., Zdrahal, Z., Hlosta, M., \& Naydenova, G. (2017). Implementing predictive learning analytics on a large scale: The teacher's perspective. Paper presented at the Proceedings of the Seventh International learning analytics \& knowledge conference, Vancouver, British Columbia.

Herodotou, C., Rienties, B., Verdin, B., \& Boroowa, A. (2019). Predictive learning analytics 'at scale': Guidelines to successful implementation in higher education. Journal of Learning Analytics, 6(1), 85-95.

Joksimović, S., Gašević, D., Loughin, T. M., Kovanović, V., \& Hatala, M. (2015). Learning at distance: Effects of interaction traces on academic achievement. Computers \& Education, 87, 204-217. https:// doi.org/10.1016/j.compedu.2015.07.002.

Kuzilek, J., Hlosta, M., Herrmannova, D., Zdrahal, Z., \& Wolff, A. (2015). OU analyse: Analysing at-risk students at The Open University. Learning Analytics Review, LAK15-1, pp. 1-16.

Kvale, S. (1996). Interviews: An introduction to qualitative research interviewing. London: SAGE Publications.

Liu, F., \& Cavanaugh, C. (2012). Factors influencing student academic performance in online high school algebra. Open Learning: The Journal of Open, Distance and e-Learning, 27(2), 149-167. https://doi. org/10.1080/02680513.2012.678613.

Ma, J., Han, X., Yang, J., \& Cheng, J. (2015). Examining the necessary condition for engagement in an online learning environment based on learning analytics approach: The role of the instructor. The Internet and Higher Education, 24, 26-34. https://doi.org/10.1016/j.iheduc.2014.09.005. 
Macfadyen, L. P., \& Dawson, S. (2010). Mining LMS data to develop an "early warning system" for educators: A proof of concept. Computers \& Education, 54(2), 588-599. https://doi.org/10.1016/j. compedu.2009.09.008.

Mazzolini, M., \& Maddison, S. (2003). Sage, guide or ghost? The effect of instructor intervention on student participation in online discussion forums. Computers \& Education, 40(3), 237-253.

McKenney, S., \& Mor, Y. (2015). Supporting teachers in data-informed educational design. British Journal of Educational Technology, 46(2), 265-279. https://doi.org/10.1111/bjet.12262.

Mor, Y., Ferguson, R., \& Wasson, B. (2015). Editorial: Learning design, teacher inquiry into student learning and learning analytics: A call for action. British Journal of Educational Technology, 46(2), 221-229. https://doi.org/10.1111/bjet.12273.

Nguyen, Q., Rienties, B., Toetenel, L., Ferguson, F., \& Whitelock, D. (2017). Examining the designs of computer-based assessment and its impact on student engagement, satisfaction, and pass rates. Computers in Human Behavior, 76, 703-714. https://doi.org/10.1016/j.chb.2017.03.028.

Norton, L., Richardson, T., Hartley, J., Newstead, S., \& Mayes, J. (2005). Teachers' beliefs and intentions concerning teaching in higher education. Higher Education, 50(4), 537-571.

Open University UK. (2014). Ethical use of student data for learning analytics policy. Retrieved June 23, 2016, from http://www.open.ac.uk/students/charter/essential-documents/ethical-use-student-datalearning-analytics-policy

Papamitsiou, Z., \& Economides, A. (2014). Learning analytics and educational data mining in practice: A systematic literature review of empirical evidence. Educational Technology \& Society, 17(4), 49-64.

Piderit, S. K. (2000). Rethinking resistance and recognizing ambivalence: A multidimensional view of attitudes toward an organizational change. The Academy of Management Review, 25(4), 783-794. https://doi.org/10.2307/259206.

Pituch, K. A., \& Lee, Y.-K. (2006). The influence of system characteristics on e-learning use. Computers \& Education, 47(2), 222-244. https://doi.org/10.1016/j.compedu.2004.10.007.

Pynoo, B., Devolder, P., Tondeur, J., van Braak, J., Duyck, W., \& Duyck, P. (2011). Predicting secondary school teachers' acceptance and use of a digital learning environment: A cross-sectional study. Computers in Human Behavior, 27(1), 568-575. https://doi.org/10.1016/j.chb.2010.10.005.

Richardson, J. T. E. (2013). Approaches to studying across the adult life span: Evidence from distance education. Learning and Individual Differences, 26, 74-80. https://doi.org/10.1016/j.lindi f.2013.04.012.

Rienties, B. (2014). Understanding academics' resistance towards (online) student evaluation. Assessment \& Evaluation in Higher Education, 39(8), 987-1001. https://doi.org/10.1080/02602 938.2014.880777.

Rienties, B., Boroowa, A., Cross, S., Kubiak, C., Mayles, K., \& Murphy, S. (2016a). Analytics4Action evaluation framework: A review of evidence-based learning analytics interventions at Open University UK. Journal of Interactive Media in Education, 1(2), 1-12. https://doi.org/10.5334/jime.394.

Rienties, B., Brouwer, N., \& Lygo-Baker, S. (2013). The effects of online professional development on higher education teachers' beliefs and intentions towards learning facilitation and technology. Teaching and Teacher Education, 29, 122-131. https://doi.org/10.1016/j.tate.2012.09.002.

Rienties, B., Cross, S., \& Zdrahal, Z. (2016b). Implementing a learning analytics intervention and evaluation framework: What works? In B. K. Daniel (Ed.), Big data and learning analytics in higher education: Current theory and practice (pp. 147-166). Heidelberg: Springer.

Rienties, B., Giesbers, S., Lygo-Baker, S., Ma, S., \& Rees, R. (2016c). Why some teachers easily learn to use a new virtual learning environment: A technology acceptance perspective. Interactive Learning Environments, 24(3), 539-552. https://doi.org/10.1080/10494820.2014.881394.

Rienties, B., Herodotou, C., Olney, T., Schencks, M., \& Boroowa, A. (2018). Making sense of learning analytics dashboards: A technology acceptance perspective of 95 teachers. The International Review of Research in Open and Distributed Learning. https://doi.org/10.19173/irrodl.v19i5.3493.

Rienties, B., \& Toetenel, L. (2016). The impact of learning design on student behaviour, satisfaction and performance: A cross-institutional comparison across 151 modules. Computers in Human Behavior, 60, 333-341. https://doi.org/10.1016/j.chb.2016.02.074.

Romero, C., López, M.-I., Luna, J.-M., \& Ventura, S. (2013). Predicting students' final performance from participation in on-line discussion forums. Computers \& Education, 68, 458-472. https://doi. org/10.1016/j.compedu.2013.06.009.

Sanchez-Franco, M. J. (2010). WebCT-The quasimoderating effect of perceived affective quality on an extending technology acceptance model. Computers \& Education, 54(1), 37-46. https://doi. org/10.1016/j.compedu.2009.07.005. 
Simpson, O. (2013). Supporting students for success in online and distance education. New York: Routledge.

Šumak, B., Heričko, M., \& Pušnik, M. (2011). A meta-analysis of e-learning technology acceptance: The role of user types and e-learning technology types. Computers in Human Behavior, 27(6), 2067-2077. https://doi.org/10.1016/j.chb.2011.08.005.

Tanes, Z., Arnold, K. E., King, A. S., \& Remnet, M. A. (2011). Using signals for appropriate feedback: Perceptions and practices. Computers \& Education, 57(4), 2414-2422. https://doi.org/10.1016/j. compedu.2011.05.016.

Tempelaar, D. T., Rienties, B., \& Giesbers, B. (2015). In search for the most informative data for feedback generation: Learning analytics in a data-rich context. Computers in Human Behavior, 47, 157-167. https://doi.org/10.1016/j.chb.2014.05.038.

Teo, T. (2010). A path analysis of pre-service teachers' attitudes to computer use: Applying and extending the technology acceptance model in an educational context. Interactive Learning Environments, 18(1), 65-79. https://doi.org/10.1080/10494820802231327.

Teo, T., \& Zhou, M. (2016). The influence of teachers' conceptions of teaching and learning on their technology acceptance. Interactive Learning Environments. https://doi.org/10.1080/10494 820.2016.1143844.

Torgerson, D. J., \& Torgerson, C. (2008). Designing randomised trials in health, education and the social sciences: An introduction. London: Palgrave Macmillan.

van Leeuwen, A. (2018). Teachers' perceptions of the usability of learning analytics reports in a flipped university course: When and how does information become actionable knowledge? Educational Technology Research and Development. https://doi.org/10.1007/s11423-018-09639-y.

van Leeuwen, A., Janssen, J., Erkens, G., \& Brekelmans, M. (2014). Supporting teachers in guiding collaborating students: Effects of learning analytics in CSCL. Computers \& Education, 79, 28-39. https://doi.org/10.1016/j.compedu.2014.07.007.

van Leeuwen, A., Janssen, J., Erkens, G., \& Brekelmans, M. (2015). Teacher regulation of cognitive activities during student collaboration: Effects of learning analytics. Computers \& Education, 90, 80-94. https://doi.org/10.1016/j.compedu.2015.09.006.

Verbert, K., Duval, E., Klerkx, J., Govaerts, S., \& Santos, J. L. (2013). Learning analytics dashboard applications. American Behavioral Scientist, 57(10), 1500-1509. https://doi.org/10.1177/00027 64213479363.

Viberg, O., Hatakka, M., Bälter, O., \& Mavroudi, A. (2018). The current landscape of learning analytics in higher education. Computers in Human Behavior, 89, 98-110. https://doi.org/10.1016/j. chb.2018.07.027.

Wolff, A., Zdrahal, Z., Herrmannova, D., Kuzilek, J., \& Hlosta, M. (2014). Developing predictive models for early detection of at-risk students on distance learning modules, Workshop: machine learning and learning analytics. Paper presented at the learning analytics and knowledge (2014), Indianapolis.

Wolff, A., Zdrahal, Z., Nikolov, A., \& Pantucek, M. (2013). Improving retention: Predicting at-risk students by analysing clicking behaviour in a virtual learning environment. Paper presented at the Proceedings of the Third International Conference on learning analytics and knowledge, Indianapolis.

Publisher's Note Springer Nature remains neutral with regard to jurisdictional claims in published maps and institutional affiliations.

Christothea Herodotou is an Associate Professor at the Open University, UK. She is interested in the evidence-based design and evaluation of technologies for learning (web-based platforms, mobile applications, digital games) through innovative research methodologies including learning analytics. She is a Senior Fellow of the Higher Education Academy (HEA).

Bart Rienties is Professor of Learning Analytics. He is the programme director of Learning Analytics at the Institute of Educational Technology, Open University, UK, and head of Data Wranglers, whereby he leads a group of learning analytics academics who conduct evidence-based research and sense making of Big Data.

Avinash Boroowa is the Project Lead of the Early Alert Indicators Project, a strategic initiative at the Open University, UK. He leads a multi-disciplinary team of senior academics, data scientists, data analysts and developers, providing thought leadership in the deployment of predictive analytics to support students. 
Zdenek Zdrahal is Professor of Knowledge Engineering. He conceived the OU Analyse (2014-present) concept, which builds on his JISC project RETAIN (2011-2012) and the MSR-OU project with the MS Research Cambridge.

Martin Hlosta is the technical lead and data scientist of OU Analyse. He has developed the predictive models and he leads the design of OU Analyse, and its integration with OU systems. 